\title{
CHOLESTEROL CRYSTALS IN THE ANTERIOR CHAMBER*
}

\author{
BY \\ SURESH KUMAR \\ Muslim University Institute of Ophthalmology. Aligarh, India
}

THE occurrence of crystals in the anterior chamber of the eye is extremely rare. Parfait-Landrau(1828) first reported the presence of crystals in the living eye. Schmidt (1831) observed a shower of silver and gold dust gush forth when he opened the anterior chamber of an eye blind for years. Blasius (1852) mentioned that 24 cases had been reported, rather a large number considering the rarity of the condition. Lloyd (1928) reviewed the literature and reported a case with a 20 -year history of injury, having hypermature cataract and shining crystals suspended in the chamber fluid. Gruber (1955) surveyed the literature for well-authenticated cases of crystals in the anterior chamber, and collected fifteen, to which he added six more (including two patients of Bonaccolto, 1937), a total of 21 . Subsequently reports were published by Akiya (1956), Sabbadini and Dugnani (1957), and Georgiades (1957). Forsius (1961) carried out a clinical and chemical study of seven cases and compared his results with a control group of six eyes. His observations did not reveal any appreciable difference in the cholesterol, protein, and total fat values of the aqueous humour and vitreous of the two groups. The albumen content of the anterior chamber and vitreous, however, was on the whole slightly lower in the subjects with cholesterol deposits in the anterior chamber. Forsius did not mention any method, other than microscopy, of identifying the crystals.

The following case is the first to be reported from India. It is of additional interest because the crystal deposits were observed in the anterior chamber of a microphthalmic eye, an event not so far recorded in the literature. Following the scheme outlined by Gruber, the nature of the crystals was determined by both microscopic examination and chemical analysis.

\section{Case Report}

An 11-year-old girl was brought by her parents to the Gandhi Eye Hospital, Aligarh, on Oct. 17, 1961. She complained of excessive lacrimation with pain and redness in the left eye for one month.

History.-The left eye had been small from birth and at the age of 4 years she developed a convergent squint in this eye. She was examined at that time by the late Dr. Mohan Lal

* Received for publication June 12, 1962. 
at this hospital and except for microphthalmos and convergent squint, the eye showed no other congenital abnormality. Vision was only perception of light.

The right eye was normal with visual acuity $6 / 6$.

Late in September, 1961, she suddenly developed a haemorrhage in the left eye. The mother noticed that the "black" of the eye had become dark red and the "white" papt also much congested. The patient was treated at the Medical College, Lucknow; the blood absorbed in 2 weeks and the redness decreased, but the mother noticed an opacity in the lower part of the cornea, and the child was brought to this hospital for a second opinion.

Examination.-The left palpebral aperture was narrow and there was pseudo-ptosis. Light projected upon the eye from a pen-torch showed myriads of shining partict scattered over the surface of the iris, in the pupillary area, anterior chamber, and back of the cornea. The eye itself was small (corneal diameter $8 \mathrm{~mm}$.), with marked conjunctivial and pericorneal injection. A dark-brown pigmented ring $1 \mathrm{~mm}$. wide encircled the entife limbus. The cornea was clear and the depth of the anterior chamber appeared to be normal. The lower half of the iris was covered by a mass of the white deposit lying in the lower part of the chamber (Fig. 1). The pupil was fixed and narrow and an exudatife membrane occupied its aperture. The fundus reflex was absent and there was no perception of light. The ocular tension recorded with the Schiötz tonometer and by applanation was $37 \mathrm{~mm} . \mathrm{Hg}$ in the left eye and $18 \mathrm{~mm} . \mathrm{Hg}$ in the right.

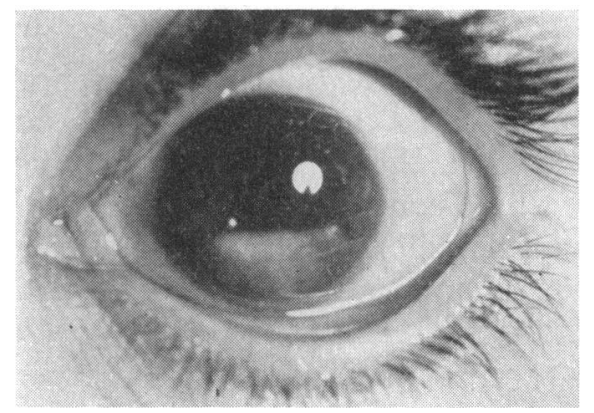

Fig. 1.-Lower half of anterior chamber occupied by mass of cholesterol crystals, some presenting a shimmering appearance. The pupil is narrow and a membrane is present in its aperture. Note the ring of pigment all round the limbus.

Slit-lamp examination of the left eye revealed a strong flare. The deposit in the anterigr chamber consisted of a profuse mass of square and rectangular-shaped crystals, many of which presented a shimmering appearance displaying all the hues of the spectrum in the beam of light. The deposits were scattered in small islands over the entire visible injs surface. There were some deposits on the corneal endothelium, but the substantia was clear. No blood could be seen in the anterior chamber. The margin of the pupil was adherent to a greyish-white membrane occupying the entire aperture of the pupil and blocking the view of the lens. This membrane was heavily vascularized, and one vessel appeared to have been the site of a recent haemorrhage. The chamber angle was $10 \mathrm{t}$ visible in the lower half, and the upper half was largely blocked by crystal deposits.

Laboratory Investigations.-The white blood count was 8,700 per cu. $\mathrm{mm}$.; polymorp $\overrightarrow{\mathrm{h}} \mathrm{s}$ 58 per cent., lymphocytes 40 per cent., eosinophils 2 per cent.

The erythrocyte sedimentation rate (Westergren) was $9 \mathrm{~mm}$./1st hour.

The serum cholesterol was $175 \mathrm{mg}$. per cent. 
Treatment.-Enucleation of the left globe having been refused, the patient was given ung. atropine 1 per cent. three times daily, dexamethasone eye drops 1 per cent. every 2 hours, and Diamox $250 \mathrm{mg}$. by mouth thrice daily. With this treatment the tension was reduced to $22 \mathrm{~mm}$. $\mathrm{Hg}$ by the 3rd day and a paracentesis was performed on Oct. 21, 1961. The deposit in the anterior chamber was gently massaged out and collected in a test-tube by means of a fine pipette. The remaining crystals were removed by irrigation of the chamber with saline. The eye was kept bandaged for 2 days and treatment with dexamethasone and atropine was continued for one week. At the time of discharge the eye was quiet with minimal circumcorneal injection and tension of $18 \mathrm{~mm}$. $\mathrm{Hg}$. Schiötz. Some crystals were still present over the iris surface and the angle was open over a wide area with only a few scattered crystals.

\section{Examination of Crystals}

(1) Microscopic.-Material collected from the anterior chamber was centrifuged, both the supernatant fluid as well as the pellet being examined microscopically. The fluid did not show any crystals, but the pellet revealed crystals of cholesterol in the form of thin colourless transparent plates of square and rectangular shape (Fig. 2).

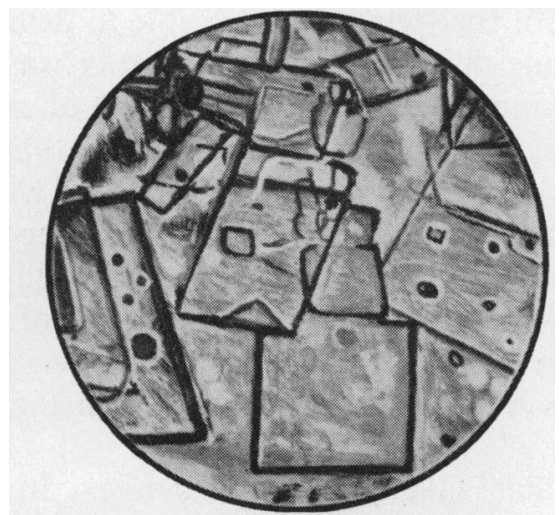

FIG. 2.-Cholesterol crystals in the form of thin colourless transparent plates, square or rectangular in shape. $\times 300$.

(2) Qualitative

(i) Some crystals were dissolved in a little chloroform and an equal volume of concentrated sulphuric acid was added. The presence of cholesterol was confirmed when a play of colours from bluish-red to cherry-red and purple was noticed in the chloroform, while the acid assumed a marked green fluorescence.

(ii) Further confirmation was obtained by the formaldehyde-sulphuric acid test. To $2 \mathrm{ml}$. of a chloroform solution of the crystals in a dry test tube, were added $2 \mathrm{ml}$. formaldehyde-sulphuric acid solution (1 part 40 per cent. formaldehyde to 50 parts of the acid). A cherry-red colour appeared in the chloroform. The chloroform was poured off into another tube and when 2 to 3 drops of acetic anhydride were added a blue colour developed.

\section{Discussion}

Cholesterol deposits have been demonstrated in most tissues of the eye, but the commonest sites are the lens, vitreous, and retina. They may occur 
as a consequence of trauma; degeneration, such as that of the vitreous; in flammation, particularly of the uveal tract; neoplasms; or after vascula episodes. In the majority of cases the eye has remained blind for a number of years as the result of trauma, and crystals have appeared in the anteriog chamber either spontaneously or during operation. Gruber (1955) found this to be the case in nine out of 21 patients studied by him. In a few cases the्ष्ट injury has resulted in retinal detachment and fluid vitreous causing synchysie scintillans. The crystals can enter the anterior chamber if the suspensoryb ligament of the lens has degenerated or if the lens has dislocated.

Hypermaturity of cataract is associated with increased cholesterol conten and calcareous degeneration of the lens. Spontaneous rupture of such 8 lens as a result of weakness in the capsule or during cataract extraction cait flood the anterior chamber with crystals. Hubbersty and Gourlay (1953) reported four interesting cases having senile cataracts, in three of whiche cholesterol crystals were demonstrated in the chamber fluid removed by paracentesis. In one of the four they were able to detect two small rents in the anterior lens capsule through which lens matter was escaping.

Forsius (1961) suggested that the causative agent of crystals in the anterior chamber was the same as the unknown mechanism that produced synchysi\& scintillans. He believed the process to be more rapid when clinically demon:strable uveitis is present, because proteins and fats enter the chamber with the flow of fluid in the eye and, as cholesterol is not readily soluble in water, 语 crystallizes easily. In the present case the author is of the opinion that the initial cause leading to spontaneous hyphaema and crystal deposition in the anterior chamber was the low grade uveitis which the patient suffered fo $\vec{E}$ some time.

Crystal deposition can take place at any age. In Gruber's study the youngest patient was 18 years old, and Forsius observed the condition in 13 -year-old boy. The maximum age reported is 83 years by Gruber and 59 by Forsius. The present patient was only 11 years old, the youngest patien⿳亠丷厂犬⿺⿻一𠃋十 in the literature seen by the author. An important factor in the depositio of the crystals seems to be the length of time for which the eye has remained blind. All the seven cases reported by Forsius had been blind for 5 years? and in Gruber's series at least six had had no sight for more than 5 years The present case, being microphthalmic, was nearly blind since birth. Such blind eyes may therefore, be considered predisposed to crystal deposition.

In some cases the condition is reversible and the crystals disappear from the chamber within a few weeks. In others the crystals persist and set up arw acute phase with lacrimation, redness, and pain, the result of mechanicaf irritation and of the rise in tension. These patients are best treated by excic sion of the globe, and as many of these eyes are blind and may be a constane source of trouble, with the further danger of sympathetic inflammation in the other eye (Sala, 1931; Forsius, 1961), this drastic treatment seems to bo justified. 


\section{Summary}

The case is reported of an 11-year-old girl with microphthalmos and cholesterol crystals in the anterior chamber.

The association of cholesterol crystals with microphthalmos has apparently not so far been noted in the literature.

Treatment with topical corticosteroids and atropine and with Diamox by mouth relieved the symptoms. Later a paracentesis was performed, and the crystals removed from the anterior chamber were identified as cholesterol by microscopic examination and chemical analysis.

\section{REFERENCES}

AKIYA, S. (1956). Acta Soc. ophthal. jap., 60, 5.

Blasius (1852). Dtsch. Klin., No. 17, p. 185 (cited by Lloyd, 1928).

BonacColto, G. (1937). Arch. Ophthal. (Chicago), 18, 476.

Forsius, H. (1961). Acta ophthal. (Kbh.), 39, 284.

Georgiades, G. (1957). Arch. Soc. ophtal. Grèce Nord, 6, 132.

Gruber, E. (1955). Amer. J. Ophthal., 40, 817.

Hubbersty, F. S., and Gourlay, J. S. (1953). Brit. J. Ophthal., 37, 432.

LloYd, R. I. (1928). Amer. J. Ophthal., 11, 271.

Parfait-LandRau (1828). Rev. Méd. franç. étrang., 4, 203 (cited by Gruber, 1955).

Sabbadini, D. and Dugnani, E. (1957). Atti Soc. oftal. Lombarda, 12, 130.

Sala, G. (1931). Boll. Oculist., 10, 453 (Zbl. Ophthal. (1932), 26, 460).

Schmidt, J. A. (1831). Z. Ophthal., 1, 350. 